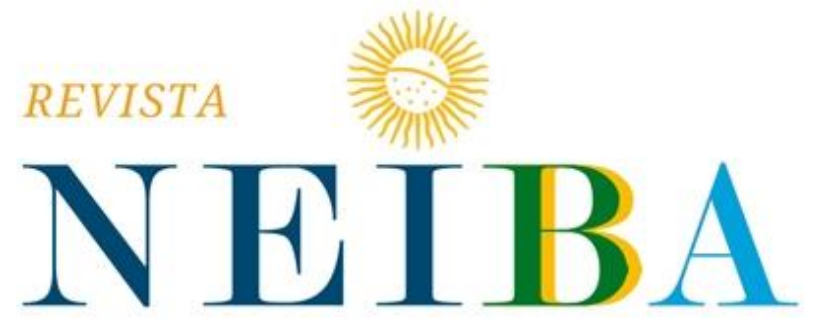

CADERNOS ARGENTINA-BRASIL

\title{
POLÍTICAS PÚBLICAS: CONCEITO, CICLO, PROCESSO DE FORMAÇÃO E SUA INEFICÁCIA NO ÂMBITO DO SISTEMA PENITENCIÁRIO BRASILEIRO
}

Public Policies: Concept, Cycle, Formation Process and its Ineffectiveness Within the Brazilian Penitentiary System

Prof. Dr. Vicente Fonseca ${ }^{1}$

Prof. Mestre Ernany Bonfim Filho²

${ }^{1}$ Centro Universitário EURO-AMERICANO, Brasília - D.F., Brasil. E-mail: vicentefonseca@hotmail.com.

${ }^{2}$ Centro Universitário EURO-AMERICANO, Brasília - D.F., Brasil. E-mail: ernanybfilho@gmail.com. ORCID: https://orcid.org/0000-0002-9765-0194

Recebido em: 22 nov. 2018 | Aceito em: 30 jun. 2019

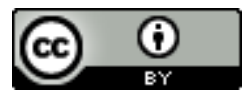

Esta obra está licenciado com uma Licença Creative Commons Atribuição 4.0 


\section{RESUMO}

A proposta do presente artigo é investigar a problemática da construção e implementação de políticas públicas para o Sistema Penitenciário Brasileiro, em especial, aquela política penitenciária voltada ao direito humano fundamental ao trabalho da pessoa, independentemente das condições nas quais se encontre. Nesse sentido, ressalta-se inicialmente a importância do entendimento do ciclo das políticas públicas, desde o surgimento do problema social até a implementação da política pública aprovada com posterior avaliação de resultados. Em um segundo momento, constata-se por intermédio de pesquisa de dados secundários, as altas taxas de reincidência penal e aumento dos delitos, de forma que as políticas públicas não estão conseguindo alcançar resultados satisfatórios. A pesquisa fundamentou-se em teóricos sobre o tema políticas públicas, além de colheita de dados secundários extraídos de fontes disponíveis no Conselho Nacional de Justiça - CNJ, Informações Penitenciárias INFOPEN e no Instituto de Pesquisas Econômicas Aplicadas - IPEA -.

Palavras-chave: Política pública; direitos humanos da pessoa presa.

\section{ABSTRACT}

The purpose of this article is to investigate the problem of the construction and implementation of public policies for the Brazilian Penitentiary System, in particular, that penitentiary policy focused on the fundamental human right to the person 's work, regardless of the conditions in which they are found. In this sense, the importance of understanding the public policy cycle, from the emergence of the social problem to the implementation of the approved public policy with subsequent evaluation of results, is emphasized initially. Secondly, through secondary data research, the high rates of criminal recidivism and increased crime are found, so that public policies are not achieving satisfactory results. The research was based on theorists on the subject of public policies, as well as the collection of secondary data extracted from sources available in the National Council of Justice (CNJ), Penitentiary Information (INFOPEN) and the Institute of Applied Economic Research (IPEA).

Keywords: Public policy, human right of the person arrested. 


\section{INTRODUÇÃO}

No presente artigo, tem-se uma pesquisa sobre o processo de formulação de políticas públicas, especialmente aquelas voltadas à ressocialização da pessoa presa ou egresso do Sistema Penal, que visam à efetivação do direito humano fundamental ao trabalho.

Inicialmente, constatou-se que há em vigor fartos comandos jurídicos de cunho constitucional, infraconstitucional, além dos Tratados de Direitos Humanos que tratam da matéria, reconhecendo o Direito Humano Fundamental ao trabalho, independentemente das condições em que se encontra a pessoa.

O artigo foi elaborado tendo como base pesquisa bibliográfica com teóricos a respeito do tema 'Políticas Públicas', bem como a colheita de dadosextraídos de fontes disponíveis no Conselho Nacional de Justiça - CNJ, no Ministério dos Direito Humanos, no Departamento Penitenciário Nacional - DEPEN e nas Informações Penitenciárias INFOPEN.

Assim, em um primeiro momento, tem-se os ciclos das políticas públicas e a necessidade de implementação daquelas voltadas ao Sistema Penitenciário, em especial, as que estão dirigidas à ressocialização pelo trabalho da pessoa presa ou do egresso do sistema penitenciário.

Inicialmente, pesquisou-se com teóricos como Michael Howlett, M. Ramesh, Antonuy Perl que tiveram importância fundamental para o entendimento do processo de formação das políticas públicas. Constatou-se que existe no Brasil uma gama enorme de regramentos a respeito de Políticas Públicas para as pessoas que cumprem penas e aquelas que já obtiveram a liberdade; entretanto, há um descaso na implementação desses mesmos dispositivos, o que acaba por causar grande taxa de reincidência penal.

Há evidente expectativa social no processo de ressocialização do prisioneiro ou egresso, e isto se justifica na medida que o corpo social tem a consciência de que um dia, mais cedo ou mais tarde, receberá a pessoa que outrora esteve privada de liberdade.Tal expectativa também está em firme compasso com um dos objetivos da Execução Penal: a harmônica integração do condenado ao meio social - Artigo 10 da Lei 
7.2101; pois o objetivo primeiro de um aprisionamento é "efetivar as disposições de sentença ou decisão criminal e proporcionando condições para a harmônica integração social do condenado e do internado."

Assim, a sociedade que receberá o egresso, deseja que tenha cumprido a pena que Ihe foi imposta, tendo sido submetido a um processo de ressocialização que o transforme em um novo cidadão, renascendo para uma vida como pessoa. Para tanto, não é possível esquecer do fato que é imperioso mostrar e possibilitar o acesso aos caminhos da ressocialização, dentre eles, o do trabalho.

\title{
CONCEITO DE POLITICAS PÚBLICAS: UMA REVISÃO DA LITERATURA
}

Inicialmente, com a finalidade de compreensão do tema, é importante trazer para o presente artigo o conceito de políticas públicas.

Daniel Vásquez e Domitile Delaplace afirmam que estamos diante de uma política pública sempre que o poder estatal, com o objetivo de buscar o bem-estar social, se utilizando de recursos próprios, leva a efeito ações para resolver, de forma eficaz e o mais racional possível, um problema público por meio de um processo de ações governamentais.

\begin{abstract}
"Para além da disputa ideológica na qual é criada a disciplina das PP, o elemento a ser destacado é o objetivo final: dar racionalidade às ações governamentais. Este é o principal objetivo da análise da PP. Cabe aí a seguinte pergunta: por que teria de me preocupar pela racionalidade da ação governamental? A resposta naquele momento era política: as democracias capitalistas deveriam superar os métodos de produção do socialismo. A resposta atualmente passa por outros lugares: a ação estatal deve estar focada no bem-estar público, tratase de uma ação pública realizada com recursos que também são públicos, porque tanto os objetivos quanto os mecanismos ou procedimentos através dos quais a ação governamental se concretiza devem fazer com que se obtenha o maior bem-estar possível da forma mais eficiente. Dessa forma, a PP tem o objetivo de encarar e resolver um problema público de forma racional através de um processo de ações governamentais."(VÁZQUEZ, 2011, pág. 36).
\end{abstract}

Neste sentido, tem-se a Política Pública como instrumento e meio de obtenção de resultados que devem caminhar em compasso com o bem-estar social, sendo pensadas,

\footnotetext{
${ }^{1}$ Art. 10 A execução penal tem por objetivo efetivar as disposições de sentença ou decisão criminal e proporcionar condições para a harmônica integração social do condenado e do internado.
} 
planejadas, construídas e aplicadas de forma eficaz e racional para a resolução dos problemas do cotidiano dos cidadãos.

Em sua definição, Thomas Dye (apud Howlett, 2013 pág. 06), entende política pública como tudo aquilo que o governo decide fazer ou não fazer.

A seu turno, Howlett entende que há três razões para considerar ação e omissão como conceito elementar de política pública, mas jamais como conceito que definiria toda e qualquer ação ou omissão governamental como política pública. Pontua que se assim o fosse, a ação de autorizar a compra de um clip como material de expediente, estaria sendo considerada como política pública tal como a declaração de uma guerra nuclear.

A primeira razão é aquela segundo a qual o agente de uma política pública é o governo, sendo este o detentor do poder delegado pelos cidadãos e o responsável pela tomada de decisões. Ademais, também detém a prerrogativa de aplicação das sanções cabíveis quando do descumprimento das normas estabelecidas.

\footnotetext{
"Em primeiro lugar, Dye especifica que o agente primário da policymaking pública é um governo. Isto significa que as decisões de um negócio privado, as decisões tomadas por organizações de caridade, grupos de interesse e outros grupos sociais ou indivíduos não são, por si, políticas públicas. Os governos têm um papel especial na policy making por força de sua capacidade de tomar decisões oficiais por meio de cidadãos, isto é, decisões sustentadas por sanções contra quem as transgredir. Por isto quando falamos em políticas públicas, estamos sempre nos referindo às iniciativas sancionadas pelos governos. Embora as atividades dos atores não governamentais possam e, muitas vezes, de fato influenciem as decisões políticas dos governos, e estes deixem as implementações de políticas públicas a cargo de organizações não-governamentais (ONGs), os esforços e iniciativas desses atores não constituem, em si, política pública." (HOWLETT, 2013, pág. 07).
}

Assim, as ações tomadas por grupos de indivíduos, entidades não-governamentais, grupos de interesses ou qualquer outro grupo social de indivíduos, não são políticas públicas, mas tão somente implemento de políticas públicas sancionadas pelo governo

A segunda razão, é que a política pública está diretamente ligada a uma decisão fundamental, referente a um direito de cidadãos, visando um fazer ou não fazer, uma ação ou omissão, sendo tal decisão invariavelmente tomada pelos políticos eleitos ou nomeados para o exercício daquela função pública. 
"Em segundo lugar, Dye destaca o fato de que a policy making envolve uma decisão fundamental de fazer ou não fazer alguma coisa a respeito de um problema e que esta decisão é tomada pelos políticos eleitos e outros funcionários oficiais. Como observa Dye, a política pública é, em sua forma mais simples, uma escolha feita no sentido de empreender um determinado curso de ação. Uma decisão negativa ou 'não decisão', isto é, nada fazer e simplesmente manter o atual curso da ação, o status quo, é uma decisão política tanto quanto a de tentar alterar alguma parte do status quo. Essas decisões 'negativas', porém, à semelhança das mais 'positivas', têm que ser deliberadas, como no caso em que um governo decide não aumentar impostos e deixa de prover fundos adicionais para as artes, serviços de saúde ou alguma outra área política de interesse."(HOWLETT, 2013, pág. 07)

Tentar alterar ou manter o status quo ante é decisão política, constituindo-se assim, verdadeira política pública de intervenção ou não intervenção em determinado ramo de atividade, setor da economia, prestação de serviço público, sendo indiferente se há ação ou omissão, fazer ou não fazer, para constituir-se em política pública, determinado desígnio vontade ou propósito de autoridade competente.

A terceira razão, ainda segundo Howlet, é aquela segundo a qual a política pública, é determinada de forma consciente e intencional, quando elege uma ação governamental em detrimento de outra, havendo evidente elemento subjetivo deliberado, em todas as ações para a consecução de resultados.

\footnotetext{
"Em terceiro lugar, e estreitamente ligada a esta, a definição de Dye também ressalta o fato de que a política pública é uma determinação consciente de um governo. Isto é, as ações e decisões do governo muitas vezes produzem efeitos não intencionados, a exemplo do que ocorre quando a iniciativa de regulamentar o consumo de cigarro ou outro vício tem por resultado que a atividade proibida torna-se clandestina e passa a operar ilegalmente como 'mercado negro'. A consequência não intencionada de uma política pública como essa não é considerada política pública, mas meramente um subproduto inesperado desta, que em alguns momentos pode ser benéfico e em outros, não. Assim é, ao menos que essa atividade subsequente, ou consequência, tenha sido especificamente prevista e intencionada pelo governo (como acontece, por exemplo, quando o aumento dos impostos sobre a gasolina desestimula o uso do automóvel e, assim, promove o uso do transporte público)." (HOWLETT, 2013, pág. 07)
}

Embora exista a intenção do gestor na consecução das políticas públicas, aquelas consequências muitas vezes não previstas ou previstas, mas não desejadas quando da 
implementação de políticas públicas traçadas, não podem ser consideradas em si, políticas públicas, mas um desdobramento causal da ação governamental.

Assim, o desvio do curso de um rio para a irrigação de determinada região não beneficiada por suas águas, tem como objetivo de política pública, contemplar uma região assolada pela seca, fixando o homem/mulher do campo em sua terra, evitando ou diminuindo assim as correntes migratórias para as grandes capitais.

Entretanto, a transposição aludida pode trazer futuramente, além do abastecimento de cisternas e irrigação de plantações, promover verdadeiro desenvolvimento econômico para a região, tendo como consequência lógica, um aumento populacional, um aumento da demanda por serviços públicos como escolas, hospitais, segurança pública, o que não estava previsto inicialmente no projeto.

A seu turno, Jenkins (apud Howlett, 2013 pág. 08), define política pública como uma decisão ou um conjunto de decisões levadas a efeito por um ou mais gestores políticos, nas quais identificam-se objetivos e meios capazes de efetivá-los.

\footnotetext{
"Jenkis (1978) define a política pública como 'um conjunto de decisões inter-relacionadas, tomadas por um ator ou grupo de atores políticos, e que dizem respeito à seleção de objetivos e de meios necessários para alcança-los, dentro de uma situação específica em que o alvo dessas decisões estaria, em princípio, ao alcance desses atores"
}

Esclarece finalmente que o objetivo final da política pública idealizada, deverá estar dentro das possibilidades do seu poder de decisão, sendo a efetiva capacidade que o ente estatal tem para implementar a política pública, fator de importância singular para escolher este ou aquele modelo de ação governamental.

Lado outro, Leonardo Secchi, define política pública como uma linha básica de ação que visa um objetivo, um norte a seguir, voltada para a resolução de questões de interesse público, determinando-se a direção que se deve tomar, de forma passiva ou de forma ativa.

\footnotetext{
“Uma política pública é uma diretriz elaborada para enfrentar um problema público. Vejamos esta definição em detalhe: uma política pública é uma orientação à atividade ou à passividade de alguém; as atividades ou passividades decorrentes dessa orientação também fazem parte da política pública; uma política pública possui dois elementos fundamentais: intencionalidade pública e resposta a um
} 
problema público; em outras palavras, a razão para o estabelecimento de uma política pública é o tratamento ou a resolução de um problema entendido como coletivamente relevante. (SECCHI, 2013, pág. 01)

Com isto, verifica-se que para se constituir em política pública, uma ação ou inação governamental deve trazer consigo os elementos da vontade deliberada, da intenção de agir ou não agir para atingir determinado fim e interesse social, resolvendo um problema público.

Celina Souza em artigo publicado na revista Sociologias, esclarece finalmente que não há que se argumentar com uma única ou com uma melhor definição de política pública.

\begin{abstract}
"Não existe uma única, nem melhor, definição sobre o que seja política pública. Mead (1995) a define como um campo dentro do estudo da política que analisa o governo à luz de grandes questões públicas e Lynn (1980), como um conjunto de ações do governo que irão produzir efeitos específicos. Peters (1986) segue o mesmo veio: política pública é a soma das atividades dos governos, que agem diretamente ou através de delegação, e que influenciam a vida dos cidadãos. Dye (1984) sintetiza a definição de política pública como "o que o governo escolhe fazer ou não fazer". A definição mais conhecida continua sendo a de Laswell, ou seja, decisões e análises sobre política pública implicam responder às seguintes questões: quem ganha o quê, por quê e que diferença faz." ${ }^{2}$
\end{abstract}

Assim, explica Celina Souza que, não havendo uma única definição, melhor ou pior para o tema, o essencial é entender que qualquer definição de política pública, mesmo aquelas mais elementares, passará, inexoravelmente, pelo lugar de desenvolvimento das preferências e ideias, qual seja o governo, e deverá responder às seguintes indagações: quem ganha o quê, por quê e que diferença faz.

\begin{abstract}
"Pode-se, então, resumir política pública como o campo do conhecimento que busca, ao mesmo tempo, "colocar o governo em ação" e/ou analisar essa ação (variável independente) e, quando necessário, propor mudanças no rumo ou curso dessas ações (variável dependente). A formulação de políticas públicas constitui-se no estágio em que os governos democráticos traduzem seus propósitos e plataformas eleitorais em programas e ações que produzirão resultados ou mudanças no mundo real." (SOUZA, 2006, pág. 24).
\end{abstract}

\footnotetext{
${ }^{2}$ SOUZA, Celina. Políticas públicas: uma revisão da literatura. Sociologias, Porto Alegre, n. 16, p. 20 a 45 de dezembro de 2006. Disponível em <http://www.scielo.br/scielo.php?script=sci_arttext\&pid=S151745222006000200003\&Ing=en\&nrm=iso>. Acesso em 30 de setembro de 2018. http://dx.doi.org/10.1590/S151745222006000200003. p. 24.
} 
Desta forma, a política pública é o campo de conhecimento cujo objetivo é a ação ou inação do governo, que necessita de análise e avaliação, para futuramente verificar a possibilidade de manutenção ou implementação de mudanças no curso destas mesmas ações ou inações. Por isto mesmo torna-se necessária uma visão holística sobre o tema, uma visão que elege o todo como mais importante do que as partes, do que os indivíduos, do que os interesses pessoais, ou mesmo do que as ideologias preconizam, aconselham ou sugerem. ${ }^{3}$

\section{POLITICA PÚBLICA: SEU PERENE CICLO POLÍTICO-ADMINISTRATIVO}

Conceituado o tema políticas públicas, salienta-se que muito antes da tomada de qualquer decisão pelo gestor público, naturalmente dentro de seu campo de atuação e visando ao interesse coletivo, tem-se um encadeamento de fases ou estágios do ciclo político-administrativo para a formulação de políticas públicas, o que visa dar racionalidade às ações governamentais.

\footnotetext{
"Como parte desse processo de racionalidade e análise, a partir da PP foi gerado o ciclo de vida das PP. A partir do nome deve-se ressaltar que se trata de um processo que nunca termina, transforma-se em um ciclo que se realimenta constante e sistematicamente. O ciclo está formado por sete processos: entrada do problema na agenda pública, estruturação do problema, conjunto das soluções possíveis, análise dos pontos positivos e negativos das mesmas, tomada de decisão, implementação e avaliação." (VAZQUEZ, 2011, pág. 36)
}

Vazquez e Delaplace esclarecem que a partir de um problema individual, surge um problema social. Este é entendido somente como um problema público quando ocorre a sua entrada na agenda pública. Esta é a primeira fase do ciclo das Políticas Públicas, que são divididas em sete fases distintas, sobrevindo a estruturação do problema, o conjunto das soluções possíveis, a análise dos pontos positivos e negativos das mesmas, a tomada de decisão, a implementação e avaliação para determinar se farão necessárias adaptações ou modificações, de forma tal que o ciclo se retroalimenta conforme ilustração.

\footnotetext{
${ }^{3}$ SOUZA, Celina. Políticas públicas: uma revisão da literatura.Sociologias, Porto Alegre, n. 16, p. 20 a 45 de dezembro de 2006. Disponível em <http://www.scielo.br/scielo.php?script=sci_arttext\&pid=S1517-

45222006000200003\&lng=en\&nrm=iso>. Acesso em 30 de setembro de 2018. http://dx.doi.org/10.1590/S151745222006000200003. p. 25.
} 
O CIClo de VIDA das políticas PÚBLICAS

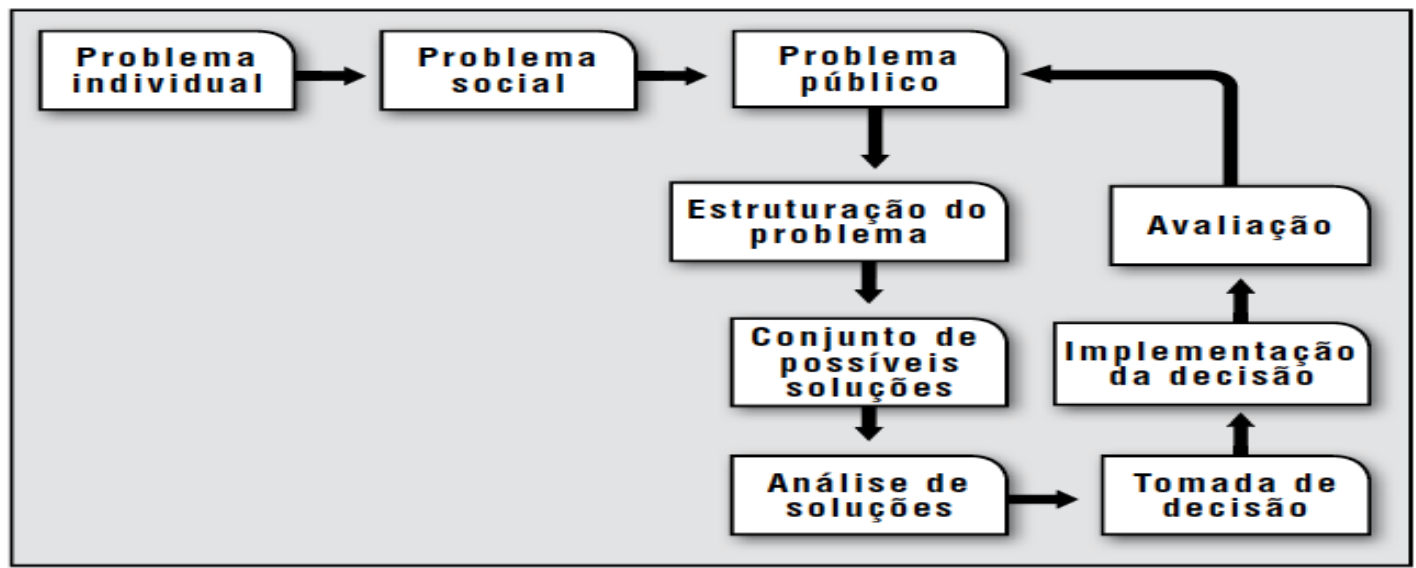

Fonte: (VAZQUEZ, 2011, pág. 36)

Esclarecem Vazquez e Delaplace, que nesta primeira fase, a entrada do problema na agenda pública, é importante observar que não é qualquer problema social que terá o status de problema público, mesmo que alguns problemas sociais afetem um número indeterminado de pessoas.

"Tudo começa com o surgimento de um problema, não de qualquer
problema, mas de um considerado "público". Esse elemento é
essencial porque existem problemas que, embora afetem muitas
pessoas (problema social), podem não ser considerados públicos. Por
exemplo, o status subordinado das mulheres durante muito tempo
não foi considerado um problema público, assim como a violência
contra a mulher também não era considerada um problema público,
mas um problema que deveria ser resolvido na esfera privada e no
qual o Estado não deveria intervir. O que atualmente é considerado
problema público, provavelmente antes não era e possivelmente
depois não será, pois a formação da agenda pública é mutante.
Quando um problema tem o status de público? Quando é recuperado
por alguma das múltiplas instituições que integram o
governo."(VAZQUEZ, 2011, pág. 36)

Assim, o chamado problema público é aquele já existe socialmente e que também foi encampado, ou seja, constituído por instituições que integram as esferas governamentais. Só assim será possível em um futuro ser estruturado de forma tal que seja possível a projeção de soluções.

\footnotetext{
"Após ser constituído o problema público, o passo seguinte é a estruturação do problema e a construção das múltiplas possíveis soluções. A estruturação do problema é a elaboração de um diagnóstico onde são especificadas as causas e as possíveis soluções
} 
do problema. Assim, de acordo com a forma em que um problema for estruturado, dependerão as diversas soluções a serem dadas ao mesmo: um problema não tem uma solução única. A estruturação dos problemas e o desenho das múltiplas soluções, junto com a tomada de decisões, são os momentos mais "políticos" do ciclo de vida da PP, onde a ideologia, os interesses e os saberes em conflito ou concorrência se superpõem." (VAZQUES, 2011, pág. 36)

Este mapeamento do 'problema público' constituiu a sua estruturação, que informará a respeito da sua gênese e sobre as possibilidades de diferentes soluções, sendo certo que para cada problema apresentado e a depender da forma de sua estruturação, várias serão as soluções, eis que serão levados em conta principalmente a ideologia e os interesses em jogo.A partir daí, tem-se como fator principal para a escolha das decisões, entre as muitas soluções apresentadas, qual a que possui maior certeza técnica. Entretanto, tal fator dependerá também da aquiescência daqueles gestores quais sejam,dos atores políticos envolvidos em sua construção.

\footnotetext{
"Finalmente, na tomada de decisões determina-se qual das múltiplas soluções possíveis é a que tem a maior certeza técnica a partir da evidência existente. Entretanto, tão importante quanto a evidência técnica é o respaldo político da escolha vencedora."(VAZQUES, 2011, pág. 36).
}

Com a estruturação e escolha da solução adequada - não esquecendo o fato de possíveis interferências ideológicas -, para o 'problema público', a política pública segue para a sua implementação e, fechando o ciclo, mas não o encerrando, tem-se a avalição.

Importante ressaltar que na fase de implementação se põe efetivamente em prática a política pública traçada e aprovada, sendo possível, mesmo após longo estudo, análise e escolha da solução mais adequada, o surgimento de alguns problemas que impedem a correta implantação.

\footnotetext{
"Após estruturar o problema público e tomar a decisão sobre a forma de resolvê-lo, põe-se em andamento a PP; este é o momento da implementação. Esse momento do ciclo é tão importante quanto os anteriores (na verdade não há uma hierarquia entre as partes que integram o ciclo). Em muitas ocasiões o problema público é devidamente estruturado e a decisão governamental não só é politicamente viável, mas também é a mais adequada para resolver esse problema. Contudo, os resultados não são os esperados. Em grande parte, isso se deve ao fato de que a realidade é complexa e
} 
nem sempre é possível prever todas as causas que modificam ou intervêm em uma PP. Também pode ter havido uma má implementação como, por exemplo, o fato de que os operadores não estejam de acordo com os objetivos da PP; isto pode acontecer com políticas muito polêmicas, como a legalização do aborto em lugares com um alto número de médicos religiosos que se neguem a praticar o procedimento clínico. Também pode suceder que, mesmo estando de acordo com os objetivos e fins da PP, a administração pública seja tão complexa em seu funcionamento que haja graves problemas de informação, de tal forma que entre os comandos superiores e os comandos operacionais as metas e os procedimentos não consigam fluir de forma clara."(VAZQUES, 2011, pág. 36)

Não são poucos os problemas e os conflitos de interesses em jogo no ciclo administrativo de vida das políticas públicas, mas antes de qualquer decisão política, verifica-se a necessidade de ser observada com muito critério a chamada fase estruturante de descoberta do problema público e de posicionamento de como será a sua solução, não podendo este mesmo gestor público atuar em benefício próprio ou de forma que lhe convier.

Muito pelo contrário, deve o gestor, após identificada a demanda social constituída em problema público, reunir sua equipe técnica, entender as circunstâncias que fizeram emergir o problema, estruturar uma política pública de forma a diminuir custos e riscos, visando atingir os melhores resultados, imaginar toda e qualquer solução possível, filtrar aquela que melhor satisfaça a demanda e assim, implementá-la para solucionar o problema eleito.

Superadas estas etapas, inclusive a de implementação, o gestor público estará apto a avaliar todos os resultados da política pública escolhida, verificando seus impactos e se houve possibilidade de atingir os resultados anteriormente desejados.

Assim, em sendo insatisfatórios ou até mesmo negativos, poderá promover eventual reajuste ou mesmo uma substituição por outras ações - políticas públicas julgadas mais eficientes.

\section{O PROCESSO DE CRIAÇÃO DAS POLÍTICAS PÚBLICAS PARA O SISTEMA CARCERÁRIO}

Uma vez realizada no tópico anterior a explanação dos pontos relevantes sobre as políticas públicas, a saber, a conceituação e os ciclos de desenvolvimento, tem-se agora o processo de formulação e implementação de políticas públicas para o Sistema 
Penitenciário brasileiro, especialmente, o respeito ao direito fundamental ao trabalho da pessoa presa e sua importância para diminuir as taxas de reincidência criminal.

Inicialmente, verifica-se que a política pública do governo federal em matéria de execução penal, visando especialmente atender às normas internacionais de proteção aos Direitos Humanos, seguiu o seu ciclo com a identificação do problema - as mazelas do cárcere e a reincidência penal, definiu a agenda, identificou alternativas, soluções, avaliou opções, implementou e identificou as consequências.

Desta forma, ainda em 1933, a partir do pensamento de juristas brasileiros como Cândido Mendes, Heitor Carrilho e Lemos de Brito, a Lei de Execuções Penais iniciou seu processo de criação, migrando de regras esparsas no Código Penal e Processo Penal para um regramento único de Execução Penal.

Entendiam os juristas citados que Código Penal Brasileiro e o Código de Processo Penal Brasileiro não eram lugares adequados para regular a execução penal, que carecia de regras próprias, fora da órbita do processo de julgamento, das fases de conhecimento e recursal. (MIRABETE, 2004, pág. 23).

E neste compasso, vislumbrando a necessidade de uma legislação própria, exclusiva para estabelecer as regras de execução penal, estabelecendo direitos, deveres, procedimento, competência, prêmios e punições aos seus atores, foi dado o primeiro passo para o 'embrião' da lei de execução penal.

Assim, naquele momento inicial foi criado pelos juristas citados o Projeto do Código Penitenciário da República de 1933, publicado no Diário do Poder Legislativo em 25 de fevereiro de 1937, se constituindo como a primeira tentativa de concentrar, em um único lugar, as regras específicas para a fase executória das penas.

Entretanto, tal projeto foi abandonado tendo em vista o advento do Estado Novo e pela consolidação, em 1940, do projeto do Código Penal Brasileiro, estando aquele em discordância com este em diversos aspectos, dentre os quais, a questão do sistema progressivo de cumprimento de penas.

Em 1951, um projeto do Deputado Carvalho Neto, resultou na aprovação da lei 3.274 de 02 de outubro de 1957, dispondo sobre as normas gerais de regime 
penitenciário. Tal regramento jurídico se mostrou inócuo, uma vez que não havia previsão de sanções pelo descumprimento dos princípios e regras ali constantes.

Na tentativa de impor maior efetividade à execução penal, em 28 de abril de 1957 foi apresentado o anteprojeto do Código Penitenciário ao Ministro da Justiça Nereu de Oliveira Ramos. Entretanto tal anteprojeto foi abandonado.

Em 1963, outro renomado jurista, Roberto Lyra Filho, redigiu o anteprojeto denominado Código de Execuções Penais, abandonado por desinteresse do seu autor, uma vez que se avizinhou o movimento político de 1964.

Já em 1970, Benjamim Moraes Filho elaborou o novo anteprojeto do Código de Execuções Penais. O anteprojeto foi encaminhado à análise pela comissão revisora composta pelos juristas José Frederico Marques, José Salgado Martins e José Carlos Moreira Alves. Mais tarde, em 29 de outubro de 1970, foi encaminhado ao então Ministro da Justiça, Alfredo Buzaid ${ }^{4}$, que da mesma forma do seu antecessor, acabou esquecido e abandonado.

Por derradeiro, em 1981, Francisco de Assis Toledo, René Ariel Dotti, Miguel Reale Junior, Ricardo Antunes Andreucci, Rogério Lauria Tucci, Sérgio Marcos de Moraes Pitombo, Benjamim Moraes Filho e Negi Calixto, integravam a comissão instituída pelo Ministro da Justiça à época, Ibrahim Abi-ackel ${ }^{5}$ com o objetivo de elaboração do anteprojeto da Lei de Execuções Penais.

Em 1983, o Presidente da República João Batista Figueiredo encaminhou o projeto ao Congresso Nacional, tendo a partir dali, sido aprovada a nova Lei de Execuções Penais, publicada no dia 13 de julho de 1984.

Verifica-se nesse breve passeio pela história, que foram algumas tentativas de codificação de um regramento nacional para a execução penal, tendo sido transcorridos 49 (quarenta e nove) anos entre o primeiro, Código Penitenciário da República, e o último, Lei de Execuções Penais de 1984. Tal fato demonstra, sem dúvidas, verdadeiro descaso no processo de criação de políticas públicas para o Sistema Penitenciário Brasileiro.

\footnotetext{
${ }^{4}$ Disponível em: http://www.justica.gov.br/Acesso/institucional/uma-breve-historia. Acesso em 25 de agosto de 2018.

5 Disponível em: http://www.justica.gov.br/Acesso/institucional/uma-breve-historia. Acesso em 25 de agosto de 2018.
} 
Atualmente, a legislação de regência em execução penal, como já dito, é a Lei 7.210 de 11 de julho de 1984, cuja Exposição de Motivos da Lei de Execuções Penais ${ }^{6}$ informa que a problemática penitenciária no Brasil, necessita de regras próprias, em um sistema federal codificado, assim possibilitando a discussão de forma homogênea em todo o território nacional.

Desta forma, não haveria argumentos plausíveis para a manutenção de regramentos regionais próprios, a cada ente federativo, o que causaria insegurança jurídica no país na medida em que decisões discrepantes poderiam ser tomadas em casos similares.

Assim, entendeu-se que somente uma lei especial, abrangente para a matéria, em especial, para a questão administrativa penitenciária e o papel jurisdicional, o tratamento penitenciário em suas diversas fases, traria um norte único a seguir para todo o país.

A aglutinação das normas de execução penal em uma lei específica, não retira a possibilidade de também estarem presentes em outros instrumentos legais, como a Constituição Federal, quando por exemplo assegura a individualização da pena, a proibição de trabalhos forçados, o respeito à integridade física e moral, a distinção de estabelecimentos prisionais de acordo com o sexo, a natureza do delito, a idade do sentenciado 7 .

A Exposição de Motivos da Lei de Execuções Penais, em seus itens 13 e 148 ${ }^{8}$, nos informa que, o que se pretende com a nova lei, é realizar a proteção dos bens jurídicos e a reincorporação do sentenciado ao meio social.

\footnotetext{
$6 \quad$ Disponível em: $\quad$ http://www2.camara.leg.br/legin/fed/lei/1980-1987/lei-7210-11-julho-1984-356938exposicaodemotivos-149285-pl.html. Acesso em 25 de agosto de 2018.

${ }^{7}$ Artigo 5o, XLVI - a lei regulará a individualização da pena e adotará, entre outras, as seguintes: a) privação ou restrição da liberdade; b) perda de bens; c) multa; d) prestação social alternativa; e) suspensão ou interdição de direitos; XLVII - não haverá penas: a) de morte, salvo em caso de guerra declarada, nos termos do art. 84, XIX; b) de caráter perpétuo; c) de trabalhos forçados; d) de banimento; e) cruéis; XLVIII - a pena será cumprida em estabelecimentos distintos, de acordo com a natureza do delito, a idade e o sexo do apenado; XLIX - é assegurado aos presos o respeito à integridade física e moral.

8 Art. 13. Contém o artigo 1 o duas ordens de finalidades: a correta efetivação dos mandamentos existentes nas sentenças ou outras decisões, destinados a reprimir e a prevenir os delitos, e a oferta de meios pelos quais os apenados e os submetidos às medidas de segurança venham a ter participação construtiva na comunhão social.14. Sem questionar profundamente a grande temática das finalidades da pena, curva-se o Projeto, na esteira das concepções menos sujeitas à polêmica doutrinária, ao princípio de que as penas e medidas de segurança devem realizar a proteção dos bens jurídicos e a reincorporação do autor à comunidade. 188. Devo recomendar especialmente a Vossa Excelência os juristas mencionados, que tudo fizeram, com sacrifício de suas atividades
} 
Esclarece também a Exposição de Motivos que a Lei anterior - Lei 3.274/57 -, que regulava a matéria, por ausência absoluta de coercibilidade, era ineficaz e, por consequência, inaplicável, vale dizer, quando descumprida não havia qualquer sanção prevista ao violador da norma.

184. Atualmente o chamado Direito Penitenciário em nosso País é reduzido a meras proclamações otimistas oriundas de princípios gerais e regras de proteção dos condenados ou internados. As normas gerais do regime penitenciário, caracterizadas na Lei no 3.274/57, não são verdadeiras normas jurídicas: materialmente, porque ineficazes, nos casos concretos e, assim, inaplicáveis; formalmente, porque não contém o elemento de coercibilidade, consistente na sanção para o descumprimento do comando emergente da norma. O referido diploma é sistematicamente ignorado, e ao longo de sua existência mais de vinte anos - não ensejou o desenvolvimento da doutrina sensibilizou juízes tribunais e a própria administração pública. ${ }^{9}$

Sob outro fundamento, desta feita no campo prático e visando a pessoa sentenciada, a nova lei pretende diminuir as taxas de reincidência penal, com tratamento humanizado, possibilidade de estudo, trabalho e qualificação profissional ao longo do cumprimento da pena.

185. As unidades federativas, sob a orientação do novo diploma, devem prestar a necessária contribuição para que a frente de luta aberta contra a violência e a criminalidade possa alcançar bons resultados no campo prático, atenuando o sentimento de insegurança oriundo dos índices preocupantes da reincidência. O apoio da União é também fator poderoso para que o sistema de execução das penas e das medidas de segurança possa contar com os padrões científicos e humanos apropriados ao progresso social e cultural de nosso País. ${ }^{10}$

Nesse objetivo, o que se pretende com a nova lei é buscar de forma efetiva a reintegração social da pessoa, o que não é somente um benefício para o sentenciado, mas para o corpo social que um dia o receberá. Nesse compasso, ainda em seu artigo

normais, para que o Projeto alcançasse o estágio agora apresentado. Os trabalhos sintetizam a esperança e os esforços voltados para a causa universal do aprimoramento da pessoa humana e do progresso espiritual da comunidade.

9 BRASIL. Exposição de motivos número 213 de 09 de maio de 1983 da Lei de Execução Penal. Disponível em: http://www2.camara.leg.br/legin/fed/lei/1980-1987/lei-7210-11-julho-1984-356938-exposicaodemotivos-149285pl.html. Acesso em: 25 de agosto de 2018.

10 BRASIL. Exposição de motivos número 213 de 09 de maio de 1983 da Lei de Execução Penal. Disponível em: http://www2.camara.leg.br/legin/fed/lei/1980-1987/lei-7210-11-julho-1984-356938-exposicaodemotivos-149285pl.html. Acesso em: 25 de agosto de 2018. 
1ํ, resta estabelecido os dois objetivos: a efetivação do comando em sentença criminal e a harmônica reinserção social do condenado ${ }^{11}$.

E segue, desta feita em seu artigo 3ำ, informa sobre a necessidade de manutenção de todos os direitos não atingidos na sentença ${ }^{12}$.

Prosseguindo a lei, seu artigo 10으, demonstra a clara preocupação do legislador com a recuperação da pessoa presa, entendendo que a assistência - material, saúde, jurídica, educacional, social, religiosa, laborativa, etc. - são pilares para um saudável retorno ao convívio social ${ }^{13}$.

Assim, verifica-se com facilidade que a Lei de Execuções Penais, em firme compasso com o Comitê Permanente de Prevenção ao Crime e Justiça das Nações Unidas, do qual o Brasil é membro, que nos trouxe as Regras Mínimas para o Tratamento do Preso no Brasil, Resolução número 14 de 11 de novembro de 1994, acabaram por criar um aparato jurídico de direitos fundamentais às pessoas presas.

Especificamente com relação ao direito humano fundamental ao trabalho, foi recentemente editada a Portaria número 003 de 03 de abril de 2018, da Vara de Execuções Penais do Distrito Federal, regulando o trabalho da pessoa presa, estabelecendo critérios de classificação para atividades laborais internas e externas.

Entretanto, para a efetivação de tal aparato de direitos fundamentais, se faz necessário que a política pública traçada e normatizada, seja realmente efetivada no mundo concreto. Entretanto, não é isto que se observa ao se constatar que dados revelam não haver implementação daquela vontade política na realidade do sistema prisional brasileiro.

\section{O DESCOMPASSO DA NORMA INSTITUÍDA COM A REALIDADE DO SISTEMA PRISIONAL VERIFICADA EM NÚMEROS}

Observa-se no capítulo anterior, que a legislação pátria caminha de maneira coerente com os tratados de direitos humanos internacionais. Lado outro, observa-se que

\footnotetext{
${ }^{11}$ Art. 1ํ A execução penal tem por objetivo efetivar as disposições de sentença ou decisão criminal e proporcionar condições para a harmônica integração social do condenado e do internado.

12 Art. 3ํ Ao condenado e ao internado serão assegurados todos os direitos não atingidos pela sentença ou pela lei.

Parágrafo único. Não haverá qualquer distinção de natureza racial, social, religiosa ou política.

${ }^{13}$ Art. 10. A assistência ao preso e ao internado é dever do Estado, objetivando prevenir o crime e orientar o retorno à convivência em sociedade.
} 
expectativa social, em firme compasso com um dos objetivos da Execução Penal, ${ }^{14} a$ ressocialização da pessoa presa, é aquela segundo a qual o Sistema de Justiça Criminal, promova ações voltadas ao egresso do Sistema Penal Brasileiro, fazendo com que passe por um processo de ressocialização ao longo do cumprimento da pena e que o habilite como um novo cidadão.

De fato, em consulta à legislação - Tratados Internacionais ${ }^{15}$, Constituição Federal ${ }^{16}$ e normas infraconstitucionais ${ }^{17}$, pode-se perceber que o problema não reside na ausência de dispositivos legais, mas na efetivação das políticas públicas traçadas nestes dispositivos.

Entretanto, a título de exemplificação, verifica-se em dados disponibilizados no Banco Nacional de Monitoramento de Prisões $^{18}$ - BNMP - de agosto de 2018, que a população prisional na capital do país é de 17.431 homens e mulheres, com uma taxa de aprisionamento de 573,49 (quinhentos e setenta e três) pessoas presas para um grupo de 100.000 (cem mil) habitantes,. É a terceira maior taxa de aprisionamento do país, ficando atrás somente dos estados de Mato Grosso do Sul e Acre.

Desse total, apenas 2.388 (dois mil, trezentos e oitenta e oito) pessoas trabalham dentro ou fora da prisão ${ }^{19}$, aproximadamente $16 \%$ do total de pessoas presas, demonstrando com isto que a Política Pública Penitenciária de ressocialização por intermédio do trabalho não vem sendo efetivada de forma satisfatória.Assim, não raras vezes, tais normas são criadas de modo a atender tão somente, de modo formal e não efetivo, os Tratados e Convenções Internacionais nos quais o país é signatário e na

\footnotetext{
14 Artigo 1o. A execução penal tem por objetivo efetivar as disposições de sentença ou decisão criminal e proporcionar condições para a harmônica integração social do condenado e do internado.

15 D.U.D.H. Declaração Universal dos Direitos Humanos. Artigo 23. Toda a pessoa tem direito ao trabalho, à livre escolha do trabalho, a condições equitativas e satisfatórias de trabalho e à proteç̧ão contra o desemprego

16 BRASIL. Constituição Federal de 05 de outubro de 1988. Artigo 5o , inciso XIII - é livre o exercício de qualquer trabalho, ofício ou profissão, atendidas as qualificações profissionais que a lei estabelecer. Disponível em: http://www.planalto.gov.br/ccivil 03/Constituicao/Constituicao.htm. Acesso em 15 de abril de 2019.

17 BRASIL. Lei número 3.274 de 2 de outubro de 1957. Dispõe sobre normas gerais do regime penitenciário, em conformidade do que estatui o art. 5o, número XV, letra b, da Constituição Federal e amplia as atribuições da Inspetoria Geral Penitenciária. Disponível em: http://www.planalto.gov.br/ccivil_03/leis/1950-1969/L3274.htm . Acesso em 25 de agosto de 2018. 18

Disponível em: http://www.cnj.jus.br/files/conteudo/arquivo/2018/08/987409aa856db291197e81ed314499fb.pdf. acesso em 15 de abril de 2019.

19 Disponível em: http://depen.gov.br/DEPEN/depen/sisdepen/infopen/relatorio_2016_22-11.pdf. acesso em 15 de abril de 2019.
} 
prática, o direito fundamental da pessoa aprisionada é sistematicamente negado, violado e subtraído.

Veja-se que, tomando ainda a Capital da República como exemplo, somente neste ano de 2018, foram infectados 2.900 (dois mil e novecentos) presos além de Agentes Penitenciários com doenças como escabiose (sarna) e impetigo, tinea (micose), pitiríase e furunculose.

Todas são altamente transmissíveis e provocam coceira, feridas e bolhas purulentas.
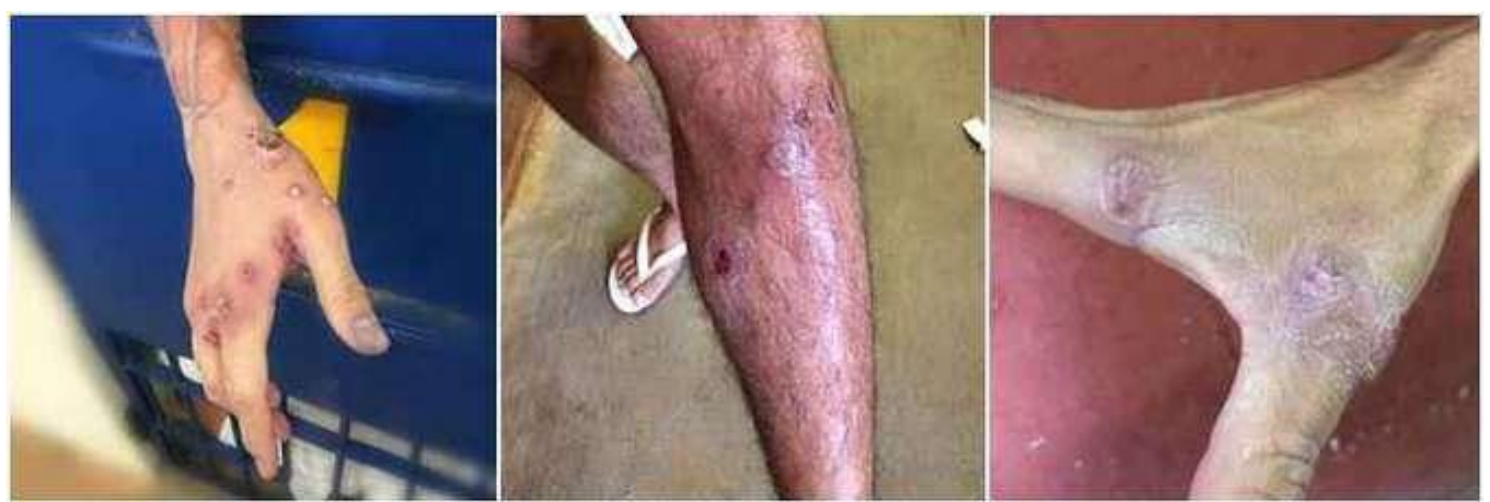

Fonte: CONJUR: doenças de pele infectam mil detentos no Distrito Federal.

Lado outro, a superlotação carcerária acaba por impedir que qualquer política pública seja efetivada, seja pelas péssimas condições de encarceramento, seja pela falta de servidores, equipe de saúde, materiais de consumo, remédios e até mesmo pelas condições arquitetônicas, conferindo à pena uma única função retribucionista, e não ressocializadora, tendo como o martírio o único instrumento de política criminal disponível.

Em tais condições de encarceramento não é possível a ressocialização do condenado por intermédio por exemplo de um processo de individualização penal, separando presos provisórios de definitivos, primários de reincidentes, delitos leves dos delitos graves, qualificando-os com o estudo e trabalho.A política ou ausência de implementação de política carcerária tem reflexo lógico e imediato na reincidência penal.

O IPEA (Instituto de Pesquisa Econômica Aplicada), entende que as taxas de reincidência criminal podem variar de 25 (pontos percentuais) - se considerado o 
conceito legal de reincidência penal ${ }^{20}{ }_{-}$, a quase 70 (setenta) pontos percentuais quando consideramos novas ingressos em Delegacias de Polícias de indivíduos que já foram internos do Sistema Penal.

Em 2015, ainda segundo o IPEA - Atlas da Violência no Brasil -, o número de homicídios chegou à marca de 30 (trinta) pessoas mortas para um grupo de 100.000 (cem mil) habitantes, lembrando ainda que o instituto referido divulga os dados dos dois anos anteriores à divulgação, portanto, dados do ano de 2015 divulgados em 2017, que podem ter sofrido significativo aumento.

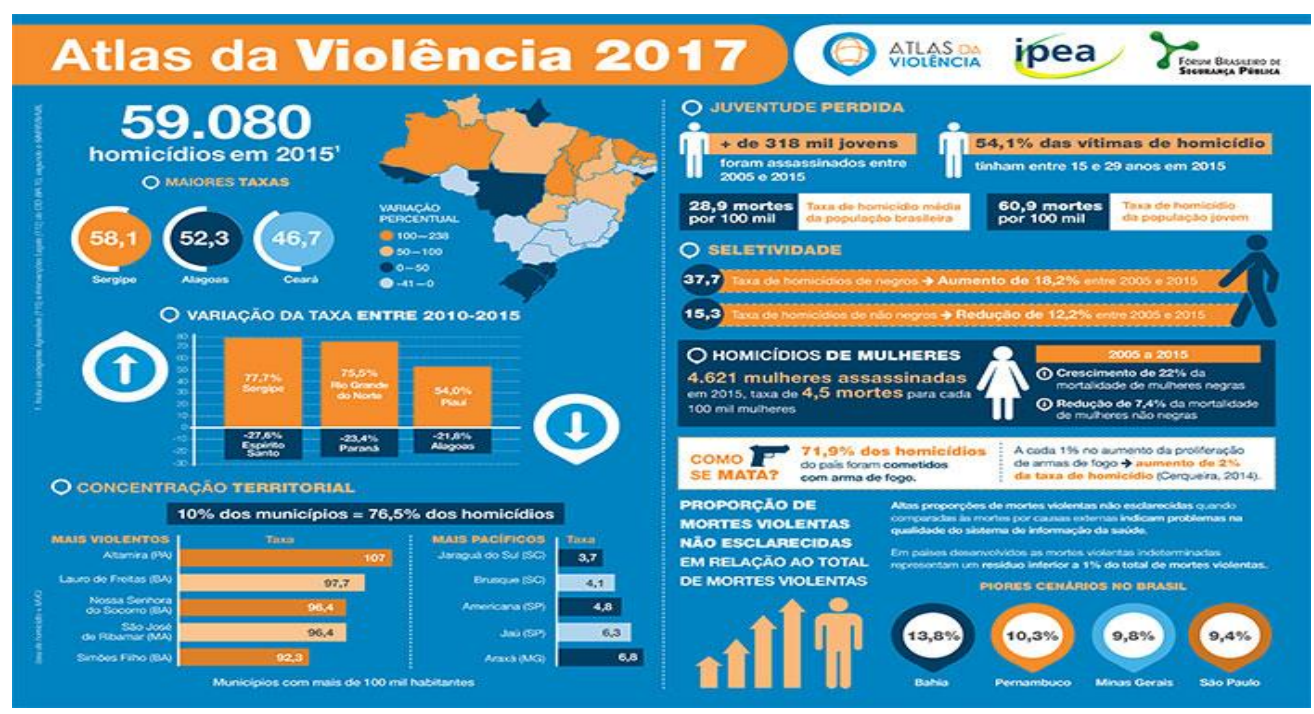

Fonte: IPEA

As políticas públicas formalizadas em decorrência da Constituição Federal de 1988, de assinatura de Tratados Internacionais de Direitos Humanos, de elaboração de legislação federal visando à ressocialização pelo estudo ou trabalho, à assistência médica, ao respeito à dignidade da pessoa humana, acabam por se tornar meros instrumentos de demonstração de que o país, ao menos no campo das ideias, cumpre o disposto nos Tratados Internacionais.

Constata-se a partir desses dados, a existência inequívoca de reiteradas violações aos direitos fundamentais da pessoa presa, como a submissão à superlotação carcerária, às ausências de condições mínimas de salubridade, de higiene, de atendimento médico hospitalar, de alimentação adequada, de condições de aeração, de promoção de estudos e trabalho, de conforto térmico, entre outros direitos mínimos

\footnotetext{
${ }^{20}$ Artigo 63. Verifica-se a reincidência quando o agente comete novo crime, depois de transitar em julgado a sentença que, no País ou no estrangeiro, o tenha condenado por crime anterior.
} 
que, como determina a lei de execuções penais, não foram atingidos pela sentença penal.

Dados do INFOPEN divulgados em dezembro de 2017 revelam que em 2016, o Sistema Penal Brasileiro tinha 368.049 vagas para uma população carcerária de 726.712, sendo a terceira maior do mundo, ficando atrás apenas de Estados Unidos e Rússia ${ }^{21}$.

O déficit de vagas no Sistema Penitenciário estava, repita-se, em 2016, ainda segundo o INFOPEN, em 358.663, com taxa de ocupação de 197,4\%.Em tais condições de superlotação carcerária, pergunta-se: É possível a implementação de políticas públicas já previstas em lei e voltadas à sua reinserção social, como por exemplo, a qualificação para o trabalho? E mais, com relação ao Direito Humano fundamental ao trabalho, verifica-se, ainda segundo dados do INFOPEN, que apenas 15\% da população carcerária no Brasil, exerce algum tipo de atividade laborativa e $87 \%$ daqueles que trabalham estão em atividades internas, como por exemplo, limpeza e conservação da unidade prisional, o que não qualifica o sentenciado para o trabalho externo.Assim, não há dúvidas que a resposta para tal questionamento é negativa, e como consequência imediata da ausência de implementação das políticas públicas penitenciárias, teremos a reincidência penal.

Como visto anteriormente, a Lei de Execuções Penais impõe a observância de diretrizes que visam à reinserção social da pessoa presa. Assim, temos a título de exemplificação, o trabalho em regime fechado, semiaberto ou aberto, com a consequente remição da pena e as autorizações para visita aos familiares.Se tais direitos forem bem delineados e efetivados, podem ser o fundamento de toda a política pública penitenciária, demonstrando a preocupação estatal com o fortalecimento dos valores da pessoa humana no sentenciado, normalmente já corrompido e degenerado pela vida pregressa e pela posterior convivência no cárcere.Assim, como política penitenciária, a implementação do direito ao estudo e ao trabalho, à manutenção de contato com os laços familiares acaba por internalizar no indivíduo preso a consciência de que ainda faz parte daquele corpo social que está, momentaneamente, impedido de

${ }^{21}$ Disponível em: http://www.justica.gov.br/news/ha-726-712-pessoas-presas-no-brasil/relatorio_2016 junho.pdf. Acesso em 19 de agosto de 2018. 
participar, mas se vê como parte deste mesmo organismo, como seu órgão, fazendo nascer a esperança de um regresso saudável ao seu meio social.

Ressalta-se aqui que a política penitenciária não pode e nem deve se circunscrever ao momento da execução da pena, especialmente em regime fechado e semiaberto, ocasiões em que o sentenciado está sob efetiva tutela estatal, vale dizer, encarcerado. A Política Penitenciária deve estar também direcionada àquele momento de obtenção dos benefícios extramuros, em semiliberdade ou liberdade total, promovendo ações de capacitação profissional e educacional.

Desta forma, o Estado deve garantir que o sentenciado em regime semiaberto, em regime aberto e mesmo após cumprida a pena, possa ser aceito pelo mercado de trabalho, promovendo incentivos, como por exemplo de ordem fiscal, para aquelas empresas que admitam em seus quadros, egressos do Sistema Penal.Entretanto, o que se verifica em política penitenciária no Brasil, é que embora exista a norma, qual seja, uma Lei de Execuções Penais, suas disposições ainda não são implementadas de forma satisfatória no Brasil.

Diante de tais números, taxas de encarceramento e de reincidência penal, o cidadão acaba por não acreditar mais na política penitenciária voltada à ressocialização da pessoa presa. A relação então mantida entre Estado, sociedade e pessoa presa se torna infalivelmente conflituosa, desarmonizada e fundada na desconfiança, com tendências às ações e discursos visando o impedimento ou diminuição de possibilidade de efetivação das políticas públicas traçadas.

Verifica-se que o cidadão confere ao Estado, na esfera criminal, o poder de estabelecer as condutas que atingem bens juridicamente protegidos, cominar abstratamente penas, iniciar um processo penal, sentenciar e executar o comando da sentença, mas não o de exceder em seu mister, sob pena de igualar-se à figura do próprio criminoso.

À sociedade cabe o direito de exigir o cumprimento do estabelecido, o direito de reivindicar, de exercer seu direito e cidadania.Entretanto, o homem é ser inacabado e caminha com o erro, e na lição de Michael Foucault, acaba por criar um instituto, a prisão que não consegue cumprir sua missão de executar a pena de forma a promover 
uma reintegração saudável do interno ao meio social (FOULCAUT, 1979, pág. 131 e 132).

Mas, do contrário que se propunha, a prisão acaba por gerar mais delinquência, perverte pessoas, aniquila espíritos, devolve à mesma sociedade que um dia proscreveu aqueles homens que delinquiram, seres mais degenerados socialmente, agora, inimigos sociais, criados e recriados pela própria política de segregação, sem objetivos, servindo a pena unicamente de instrumento de vingança social pois aquela pessoa segregada não foi objeto de ações que visassem a sua regeneração.

\begin{abstract}
"Minha hipótese é que a prisão esteve, desde sua origem, ligada a um projeto de transformação dos indivíduos. Habitualmente se acredita que a prisão era uma espécie de depósito e criminosos, depósito cujos inconvenientes se teriam constatado por seu funcionamento, de tal forma que se teria dito ser necessário reformar as prisões, fazer delas um instrumento de transformação dos indivíduos. Isto não é verdade: os textos, os programas, as declarações de intenção estão aí para mostrar. Desde o começo a prisão devia ser um instrumento tão aperfeiçoado quanto a escola, a caserna ou o hospital, e agir com precisão sobre os indivíduos. O fracasso foi imediato e registrado quase ao mesmo tempo que o próprio projeto. Desde 1820 se constata que a prisão, longe de transformar os criminosos em gente honesta, serve apenas para fabricar novos criminosos ou para afundálos ainda mais na criminalidade. Foi então que houve, como sempre nos mecanismos de poder, uma utilização estratégica daquilo que era um inconveniente. A prisão fabrica delinquentes, mas os delinquentes são úteis tanto no domínio econômico como no político." (FOULCAUT, 1979, pág. 131 e 132).
\end{abstract}

E esse comportamento social segregacionista acaba por gerar dividendos políticos advindos do encarceramento desmedido, retroalimentando o sistema de política penal e o sistema carcerário, eternizando no poder a classe política em detrimento do bem da sociedade como um todo, eis que inviabiliza a fundamento primaz da execução penal, qual seja, a ressocialização da pessoa presa. E é exatamente esse sistema excessivamente encarcerador, refletido bem em países como os Estados Unidos da América - Teoria das Broken Windows ${ }^{22}$ e Teoria dos Theree Strikes and You're Out ${ }^{23}$ que conduz à seguinte reflexão: no Brasil, ante à ausência ou deficiência na

\footnotetext{
22 Disponível em: https://media4.manhattan-institute.org/pdf/_atlantic monthly-broken windows.pdf. Acesso em 14 de abril de 2019

23 Disponível em:https://jus.com.br/artigos/18971/three-strikes-and-you-re-out: a vitimização da democracia substancial na cruzada contra a reincidência criminal In Boletim IBCCRIM ano 18, número 213, agosto de 2010, p. 13. Acesso em 14 de abril de 2019.
} 
implementação de políticas públicas voltadas à ressocialização da pessoa presa ou egresso do Sistema Penitenciário, afigura-se uma espécie de política de política pública eleita pelo Estado?

Acredita-se que a resposta a tal questionamento é positiva, eis que, conforme visto anteriormente, política pública é a ação ou inação do Estado de forma a enfrentar e solucionar um problema público. Neste sentido, alerta Howlett, alerta que "Uma decisão negativa ou 'não decisão', isto é, nada fazer e simplesmente manter o atual curso da ação, o status quo, é uma decisão política tanto quanto a de tentar alterar alguma parte do status quo."(HOWLETT, 2013, pág. 07).

E nesse sentido, a ausência ou a deficiência na implementação de políticas públicas, em determinados casos, pode ser considerada uma opção daqueles responsáveis diretamente por sua execução ou por absoluto desinteresse ou ainda por inação deliberada.

Como alerta FOULCAUT, há na verdade um sinal claro para o objeto da execução penal, o homem condenado, qual seja, um caminho sem volta, o da delinquência.

\footnotetext{
"Sim, e a prisão foi o grande instrumento de recrutamento. A partir do momento que alguém entrava na prisão se acionava um mecanismo que o tornava infame, e quando saía, não podia fazer nada senão voltar a ser delinquente." (FOULCAUT, 1979, pág. 131 e 132).
}

Neste contexto de abandono e deficiência na efetivação das políticas públicas voltadas ao Sistema Penitenciário, resta refletir sobre a reação social em relação ao interno ou egresso ao ter a consciência da ineficácia do mecanismo de ressocialização idealizado pelo Estado; e ainda, quando aplicado não funciona, não reabilita, não educa ou reeduca, não profissionaliza.

Naturalmente a reação social será a repulsa e tendência inexorável à estigmatização daqueles que foram objeto da persecução criminal, tornando-os diferentes por imposição dos órgãos que o rotularam.

Diante do quadro conhecido de abando de Políticas Públicas do Sistema Penitenciário, como esperar da sociedade alguma compreensão no sentido de que 
aquele que cumpre ou cumpriu pena terá um retorno saudável ao convívio social, se reintegrando à comunidade, uma vez que não há iniciativas para tanto.

A conclusão é a de que ao estabelecer a instituição total(GOFFMAN, 2005, pág. 16), inserindo a pessoa desviante em um programa que se apodera de sua individualidade, com a supressão de mecanismos de ressocialização, fazendo com que se enxergue como os demais também separados e rotulados, passará a se comportar com tal.

Tendo o comportamento desviante, como aquele que a sociedade entende como tal, pode-se perceber que não é possível ou quase impossível impedir a ocorrência da violação da norma anteriormente estabelecida, mas é viável e necessário promover a redução dos desvios posteriores decorrentes da estigmatização, rompendo com o ciclo vicioso estabelecido pelo Estado e sociedade, inserindo a pessoa condenada em atividades que possam lhe proporcionar um retorno saudável à sociedade.

\section{CONSIDERAÇÕES FINAIS}

Se o que se faz em matéria de políticas públicas voltadas ao egresso do Sistema Penal não produz qualquer efeito prático - v. taxas de reincidência penal já mencionadas -, vale dizer que não são efetivadas por ausência completa de vontade política, conclui-se que somente com um verdadeiro distanciamento do meio político, haverá a possiblidade de, cientificamente, serem traçadas e efetivadas estratégias que visem à comunhão entre os Princípios Constitucionais e a sua efetivação para a reinserção social saudável do indivíduo que um dia esteve privado de sua liberdade.

Nesse sentido, o artigo de Cristina Buarque de Holanda, citando Vilfredo Pareto, informa que a solução poderia estar em separar a normatização da efetivação das políticas públicas; sendo responsáveis pelas últimas, técnicos e cientistas, uma vez que estes não estariam condicionados à vontade dos partidos, mas à solução das questões.

\footnotetext{
"O verdadeiro cientista não poderia aderir a uma ou outra parte em um conflito e deveria buscar posição absolutamente imparcial. Longe de produzir orientações para a ação política, a ciência, na perspectiva proposta, apenas promove investigação objetiva da realidade. $O$ exercício científico pode produzir verdade, e não utilidade. Pareto destitui a ciência de toda intenção normativa. Dela não deriva moralidade ou sentido para a vida. A ciência pressupõe o interesse por si mesma e não dá prova científica de sua necessidade. A ciência,
} 
por fim, não produz movimento ou ação, mas compreensão da realidade". (HOLANDA, 2011, pág. 7.52)

Efetivamente, para a classe política dominante, o processo punitivo e as políticas públicas voltadas ao cárcere devem ser realizados fora dos olhos do cidadão, sendo o melhor caminho, a invisibilidade da questão carcerária, eis que as prisões e os prisioneiros, não faziam e ainda hoje não fazem parte da preocupação das lideranças políticas. Não há dividendos eleitorais e com isto, impossibilita-se a perpetuação no poder.

Diante disse, os milhares dehomens e mulheres presos e presas, uma vez não efetivadas as políticas públicas ressocializadoras, dentre as quais, a efetivação do trabalho prisional, continuarão a ser pessoas sem face e identidade, fazendo parte de um projeto político de invisibilidade, queacaba por causar a sua despersonalização e humilhação (ZAFFARONI, 2007, pág. 18), o que em nada contribuiu para o processo de ressocialização que poderia estar inserida.

Dessa forma, o Poder Público que um dia criou seu sistema punitivo, lembrando que um de seus objetivos da execução penal é o de promover a ressocialização da pessoa presa, não percebe o egresso do Sistema Penal como cidadão, facilitando seu ingresso ou retorno ao mercado de trabalho, seja admitindo-o por intermédio de concursos públicos, seja pela iniciativa privada, vedando a participação por exemplo em processos licitatórios.Enfim, o Estado, ao fechar as portas para o egresso do Sistema Penal, demonstra claramente e admite que seu sistema de ressocialização idealizado,e insuficientemente efetivado, é ineficaz, inócuo e desacreditado até mesmo por aquele que o criou. 


\section{REFERÊNCIAS BIBLIOGRÁFICAS}

FOUCAULT, Michel. Vigiar e punir: nascimento da prisão; tradução de Raquel Ramalhete. Petrópolis, Rio de Janeiro: Vozes, 1987.

GOFFMAN, Erving. Manicômios, prisões e conventos. Tradução Dante Moreira Leite. São Paulo: Perspectiva, 2005

HOWLETT, Michael. RAMESH, M. PERL, Antonuy. Política pública: seus ciclos e subsistemas. Uma abordagem integral. Tradução de Francisco G. Heidemann. Editora Elsevier. Rio de Janeiro, 2013.

HOLLANDA, Cristina Buarque de. Teorias das Elites. Zahar, 2011. (Introdução: Gaetano Mosca; Vilfredo Pareto; Robert Michels; Bases do Elitismo Democrático: Joseph Schumpeter e Robert Dahl; Marcas do Elitismo nas Origens da República Brasileira, pp. 7.52)

MIRABETE, Júlio Fabbrini. Execução penal: comentários à Lei n. 7.210, de 11 de julho de 1984. 11a ed. - Revista e atualizada - São Paulo: Atlas, 2004.

SECCHI, Leonardo. Políticas públicas: conceitos, esquemas de análise, casos práticos. 2a. ed. São Paulo: Cengace. Leranig, 2013.

SOUZA, Celina. Políticas públicas: uma revisão da literatura.Sociologias, Porto Alegre, $\mathrm{n}$. 16, p. 20 a 45 de dezembro de 2006. Disponível em $<$ http://www.scielo.br/scielo.php?script=sci_arttext\&pid=S1517-

45222006000200003\&lng=en\&nrm=iso>. Acesso em 30 de setembro de 2018. http://dx.doi.org/10.1590/S1517-45222006000200003.

VÁZQUEZ, Daniel; DELAPLACE, Domitille. Políticas Públicas na Perspectiva de Direitos Humanos: um Campo em Construção. In Revista Internacional de Direitos Humanos, v. 8, n. 14, jun. 2011. Disponível em: http://sur.conectas.org/wpcontent/uploads/2017/11/sur14-port-daniel-vazquez-e-domitille-delaplace.pdf. Acesso em 23 de setembro de 2018.

ZAFFARONI, Eugenio Raúl. O inimigo no direito penal. Tradução de Sergio Lamarão. 2a ed. Rio de Janeiro, REVAN, 2007.

ZAFFARONI, Eugenio Raúl. Manual de direito penal. Parte. 5. ed. rev. atual. São Paulo: Editora Revista dos Tribunais, 2004.

\section{DICIONÁRIOS}


FERREIRA, Aurélio Buarque de Holanda, Novo Aurélio, século XXI. Rio de Janeiro: NOVA FRONTEIRA, 1999.

\section{LEGISLAÇÃO:}

BRASIL. Anteprojeto da Lei de Execuções Penais. Disponível em:

http://www.lexml.gov.br/urn/urn:lex:br:rede.virtual.bibliotecas:livro:1970;0001498044. Acesso em 25 de agosto de 2018.

BRASIL. Exposição de Motivos número 213 de 09 de maio de 1983 da Lei de Execução Penal. Disponível em:http://www2.camara.leg.br/legin/fed/lei/1980-1987/lei-7210-11julho-1984-356938-exposicaodemotivos-149285-pl.html. Acesso em 15 de agosto de 2018.

BRASIL. Decreto N².848, de 7 de dezembro de 1940. Código Penal Brasileiro.

Disponível em: http://www.planalto.gov.br/ccivil_03/decreto-

lei/Del2848compilado.htm. Acesso em: 30 de julho de 2018.

BRASIL, Lei .3274/1957. Disponível em: http://www.planalto.gov.br/ccivil_03/leis/19501969/L3274.htm. . Acesso em 25 de agosto de 2018.

BRASIL. Lei 7.210/84. Disponível em:

http://www.planalto.gov.br/ccivil_03/leis/L7210.htmm. Acesso em 14 de abril de 2018.

BRASIL. Lei 8.072 de 25 de julho de 1990. Disponível em:

http://www.planalto.gov.br/ccivil_03/Leis/L8072.htm. Acesso em 16 de abril de 2018.

DUDH - Declaração universal dos direitos humanos.

https://www.unicef.org/brazil/pt/resources_10133.htm. Acesso em 12 de julho de 2018.

BRASIL. Constituição (1988). Constituição da República Federativa do Brasil.http://www.planalto.gov.br/ccivil_03/constituicao/constituicaocompilado.htm. Acesso em 16 de agosto de 2018.

Pacto de San José da Costa Rica. Convenção Americana sobre Direitos Humanos. Disponível em:http://www.planalto.gov.br/ccivil_03/decreto/19901994/anexo/and678-92.pdf. Acesso em 16 de setembro de 2018

BRASIL. Conselho Nacional de Justiça. CNJ. Regras de Mandela: regras mínimas das nações unidas para o tratamento do presos. Disponível em: http://www.cnj.jus.br/files/conteudo/arquivo/2016/05/39ae8bd2085fdbc4a1b02fa6e3 944ba2.pdf.Acesso em 16 de setembro de 2018. 
BRASIL. Câmara dos deputados. Regras Mínimas da ONU para o Tratamento de Reclusos, adotadas em 31 de agosto de 1955, pelo Primeiro Congresso das Nações Unidas para a Prevenção do Crime e o Tratamento dos Delinquentes. Disponível em: http://www2.camara.leg.br/atividade-legislativa/comissoes/comissoespermanentes/cdhm/comite-brasileiro-de-direitos-humanos-e-politicaexterna/RegMinTratRec.html. Acesso em 16 de setembro de 2018.

BRASIL. CÂMARA DOS DEPUTADOS. Princípios de ética médica aplicáveis à função do pessoal de saúde, especialmente aos médicos, na proteção de prisioneiros ou detidos contra a tortura e outros tratamentos ou penas cruéis, desumanos ou degradantes. Disponível em: http://www2.camara.leg.br/atividade-legislativa/comissoes/comissoespermanentes/cdhm/comite-brasileiro-de-direitos-humanos-e-politicaexterna/PrincEtMedProtPris.html Acesso em 20 de setembro de 2018.

Código Penitenciário do Distrito Federal. Lei Distrital 5969 de 16 de agosto de 2017. Disponível em:

http://biblioteca.cl.df.gov.br/dspace/bitstream/123456789/1867/1/Texto\%20integral\% 20\%28PDF\%29. Acesso em 30 de setembro de 2018.

Portaria número 003 do Tribunal de Justiça do Distrito Federal e Territórios. Disponível em : http://www.tjdft.jus.br/cidadaos/execucoes-

penais/vep/legislacao/Portarian.003.2018Trabalho.pdf/view. Acesso em 12 de outubro de 2018

Regras Mínimas para tratamento dos presos no Brasil. Disponível em: http://www.crpsp.org.br/interjustica/pdfs/regras-minimas-para-tratamento-dospresos-no-brasil.pdf.

\section{RELATÓRIOS}

Relatório Ministério da Justiça. Disponível em: http://www.justica.gov.br/news/ha-726712-pessoas-presas-no-brasil/relatorio_2016_junho.pdf. Acesso em 19 de agosto de 2018.

Relatório reincidência penal IPEA.

Disponívelem:http://www.ipea.gov.br/portal/images/stories/PDFs/relatoriopesquisa/15 0611_relatorio_reincidencia_criminal.pdf. Acesso em 19 de agosto de 2018. 